\title{
Fabrication of AA7075 Hybrid Green Metal Matrix Composites by Friction Stir Processing Technique
}

\author{
Sanjay Kumar ${ }^{1}$, Ashish Kumar Srivastava ${ }^{2 *}$, Rakesh Kumar Singh ${ }^{1}$ \\ ${ }^{1}$ Noida Institute of Engineering \& Technology, Greater Noida, GB Nagar 201306, U.P., India \\ ${ }^{2}$ G. L. Bajaj Institute of Technology \& Management, Greater Noida, GB Nagar 201306, U.P., India
}

Corresponding Author Email: ashish.srivastava@glbitm.org

https://doi.org/10.18280/acsm.440409

Received: 7 January 2020

Accepted: 21 June 2020

\section{Keywords:}

friction stir processing (FSP), hybrid green metal matrix composites (MMCs), aluminium alloys, waste management, environmentally friendly

\begin{abstract}
Friction stir processing is an avant-garde technique of producing new surface composite or changing the different properties of a material through intense, solid-state localized material plastic deformation. This change in properties depends upon the deformation formed by inserting a non-consumable revolving tool into the workpiece and travels laterally through the workpiece. This research work highlights the effect of process parameters on mechanical properties of fabricated surface composites by friction stir processing. By using various reinforcing materials like $\mathrm{Ti}, \mathrm{SiC}, \mathrm{B} 4 \mathrm{C}, \mathrm{Al}_{2} \mathrm{O}_{3}$ with waste elements like waste eggshells, rice husks, coconut shell and coir will be used to fabricate the green composites which are environmentally friendly and reduces the problem of decomposition. The parameter for this experiment is considered as the reinforcing materials, tool rotation speed and tool tilt angle. The $\mathrm{SiC} / \mathrm{Al}_{2} \mathrm{O}_{3} / \mathrm{Ti}$ along with eggshell are selected as reinforcement materials. The main effect of the reinforcement is to improve mechanical properties, like hardness, impact strength and strength. The results revealed that the process parameters significantly affect the mechanical properties of friction stir processed surface composites.
\end{abstract}

\section{INTRODUCTION}

In the current scenario, MMCs have a vast application in aircraft, automobile, structural, non-structural, marine, transportation and biomedical applications [1]. Excellent properties, like lightweight, high specific stiffness to weight ratio and high strength to weight ratio makes it very much imperative and suitable for many applications [2]. Issues such as waste management and environmental safety are becoming more important to the introduction of new materials and products. The eggshells, rice husk, coconut shell and coir have the problem of decomposition and harm the environment also. To avoid decomposition and reduce the harmful effect on the environment, the eggshells are selected as reinforcing material for the fabrication of green composites.

Friction stir processing is an innovative technology based on the Friction Stir Welding (FSW) principle that locally eliminates casting defects and refines microstructures by conveying high-level energy in the solid-state form, resulting in improved mechanical properties, increase resistance to corrosion and fatigue, enhance formability, and improve other properties [3]. FSP is also an emerging process to produce surface composites by reinforcing the different types of metal particles into the matrix in the solid-state. Figure 1 shows the schematic arrangement of FSP process used to incorporate the reinforcement particles into the matrix matrix material with the help of frictional heat.

Sarmadi et al. [4] observed that the $\mathrm{Cu}$-graphite composites have low friction coefficient and it can be used as bearing materials instead of materials containing lead which cause environmental problems. Singh Subhash and Pal Kaushik [5] analyzed the effect of texture evolution on mechanical properties and damping properties of $\mathrm{SiC} / \mathrm{ZnAl}_{2} \mathrm{O}_{4} / \mathrm{Al}$ composite fabricated by friction stir processing. Zhao et al. [6] observed in the situ nano- $\mathrm{ZrB}_{2} / 2024 \mathrm{Al}$ composites made-up from $2024 \mathrm{Al}-\mathrm{K}_{2} \mathrm{ZrF}_{6}-\mathrm{KBF}_{4}$ system were processed by FSP to achieve superplasticity of the composites. Thangarasua et al. [7] concluded that FSP was significantly influenced the distribution of $\mathrm{TiC}$ particles and sliding wear behavior of the AA6082/TiC Aluminium Matrix Composites (AMCs). Chainarong et al. [8] were evaluated about the Friction stir processing of SSM356 Aluminum Alloy. Dinaharan [9] studied the Effect of ceramic particulate types on microstructural and tensile strength of AMCs produced using FSP. Joyson et al. [10] observed that the FSP has been accepted as a potential method to produce AMCs without the disadvantages of fluid metallurgy approaches. The grains of the AA6063 were widely refined by the blend of the thermomechanical effect of FSP and the pinning effect of quartz elements. Dinaharan et al. [11] demonstrated the Microstructure and wear characterization of $\mathrm{Cu} / \mathrm{TiB}_{2}$ copper matrix composites fabricated by friction stir processing. They also observed that by reinforcing hard ceramic particles, the poor wear performance of copper is improved. Rana et al. [12] were evaluated about the fabrication of Aluminium 7075 / $\mathrm{B}_{4} \mathrm{C}$ surface composite by FSP and investigation on wear properties. They found that wear resistance is to be improved by $100 \%$ compared to the base metal. Ratna et al. [13] were concluded that surface MMCs where the surface of the material is modified by dispersing secondary phase in the form of particles or fibers and the core of the material experience no change in chemical composition and structure. Ahmadkhaniha 
et al. [14] were concluded that the composite layers containing $\sim 0.8 \%$ volume $\mathrm{Al}_{2} \mathrm{O}_{3}$ nanoparticles were produced on AZ91 magnesium alloy by Raju and Kumar [15] observed that the influence of three factors, such as volume percentage of reinforcement particles (i.e. $\mathrm{Al}_{2} \mathrm{O}_{3}$ ), tool tilt angle and concave angle of the shoulder, on the mechanical properties of $\mathrm{CueAl}_{2} \mathrm{O}_{3}$ surface composites fabricated by FSP. Rathee et al. [16] were evaluated about aluminium matrix surface composites are gaining alluring role exclusively in aerospace, defense, and marine industries. They studied, AA6061/SiC surface composites were fabricated and the effect of tool plunge depth on the pattern of reinforcement particle dispersion in the metal matrix was investigated.

In the present study, an attempt is made to optimize the set of process parameters of the friction stir process to get the desired hardness value.

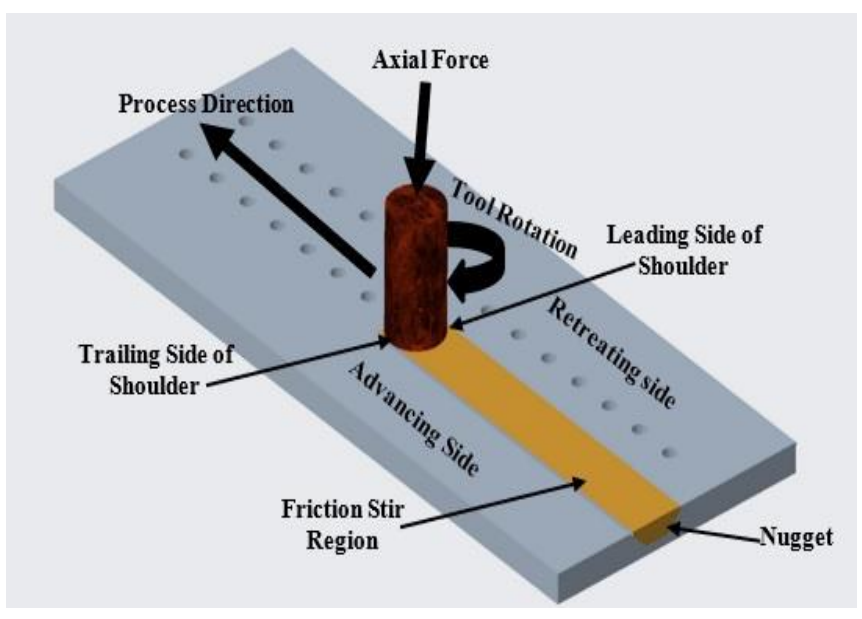

Figure 1. Schematic arrangement of FSP

\section{EXPERIMENTAL PROCEDURE}

For this study, aluminium alloys 7075 was carefully chosen for FSP. In the present day, this material is broadly used in the aerospace and automotive industries. It has better formability, corrosion-resistant and better weldability. Figure 2 shows the raw plate of AA 7075 used in this study. The reinforcement materials were selected as $\mathrm{Ti}, \mathrm{SiC}, \mathrm{Al}_{2} \mathrm{O}_{3}$, eggshell and shown in Figure 3.

Based on a critical review of the literature and some pilot experiments, the below parameters with their notations and ranges were selected and tabulated in Table 1. In this investigational study, the Taguchi method was used for producing surface composite with optimal process parameters of FSP. The Taguchi method for superior manufacturing is proposed as a guide and reference source for engineering experts who involved in product or process research, investigation and development.

All process parameters were three levels and hence, column 1 assigned to the Reinforcement, column 2 to the rotational speed and column 3 to the tool tilt. The nine rows of the L9 Orthogonal Array (OA) represent the nine experiments to be conducted during the investigation. Table 2 represents the L9 OA with a different set of parameters on which surface composite was fabricated.

The FSP tool that used to fabricate all the surface composites was a triangular pin profile as shown in Figure 4.

After the selection of base material and reinforcement, we cut the base metal $(100 \times 50 \times 10) \mathrm{mm}$ for the fabrication of surface composite. Drilling was carried out of $4 \times 5$ size of the hole on the surface of base metal as shown in Figure 5. These holes were Filled with reinforcements as per prepared proportions. The surface composites were fabricated using friction stir processing on the vertical milling machine according to L9 OA, as presented in Table 2. The experimentation procedure summarized as the workpiece was fixed with the help of clamping devices (vice) on the working table of the milling machine. The complete FSP setup with required lebels are shows in Figure 6. The fabricated FSP tool was rotating as per the descried speed according to L9 OA and by providing axial plunge it inserted in the workpiece. Due to the rotation of the tool concerning the workpiece, the frictional heat was generated and stirring the tool in the workpiece was soften. After adequate frictional heat generated, the tool was allowed to travel along the hole lines.

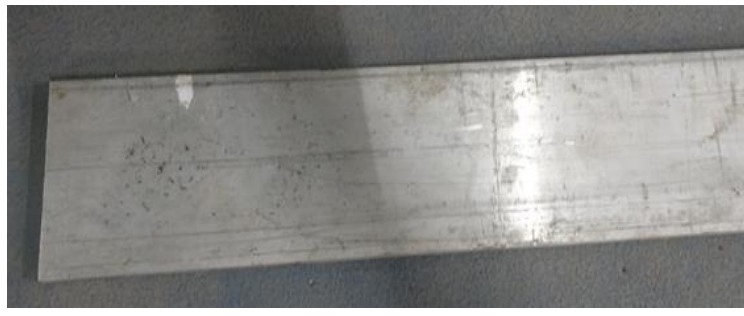

Figure 2. Aluminium alloy 7075 sheet

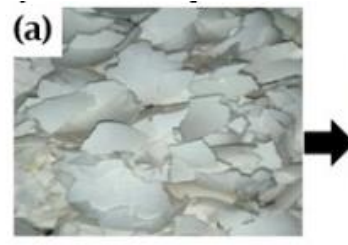

(a) Hen Eggshells (b)

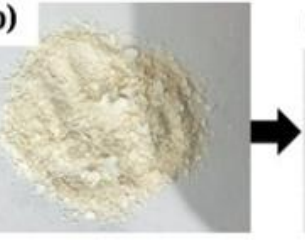

(b) Dried Eggshells

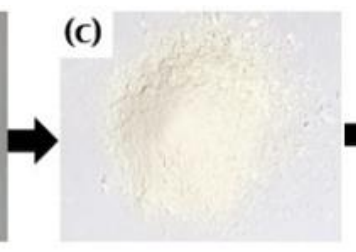

(c)Eggshells Powder

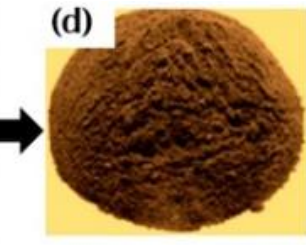

(d) Carbonized Eggshells Powder

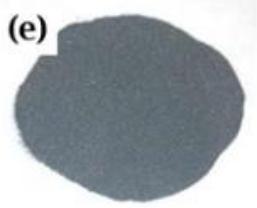

(e) $\mathrm{SiC}$

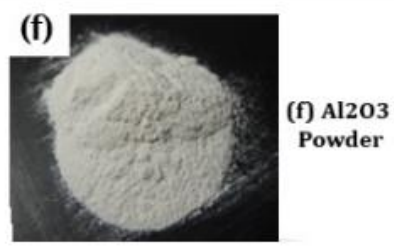

(g)

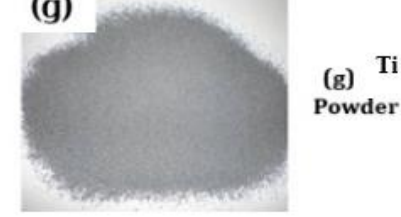

Figure 3. Reinforcement materials 
Table 1. FSP process parameters and their levels

\begin{tabular}{ccccc}
\hline & & \multicolumn{3}{c}{ Levels of factors } \\
\hline Parameters & Notation & $\mathbf{1}$ & $\mathbf{2}$ & $\mathbf{3}$ \\
\hline Reinforcement & $\mathbf{R F}$ & $\mathrm{SiC}+$ Egg Shell (SE) & $\mathrm{Al}_{2} \mathrm{O}_{3}+$ Egg Shell (AE) & Ti+ Egg Shell (TE) \\
Tool Rotational Speed $(\mathrm{rpm})$ & TS & 920 & 1550 & 2250 \\
Tool Tilt Angle $\left({ }^{0}\right)$ & TA & $1^{0}$ & $2^{0}$ & $3^{0}$ \\
\hline
\end{tabular}

Table 2. Standard L9 orthogonal array (OA)

\begin{tabular}{clcc}
\hline S. No. & Reinforcement (RF) & Tool Speed in rpm (TS) & Tilt Angle in degree (TA) \\
\hline 1 & $\mathrm{SiC}+$ Egg Shell (SE) & 920 & $1^{0}$ \\
2 & $\mathrm{SiC}+$ Egg Shell (SE) & 1550 & $2^{0}$ \\
3 & $\mathrm{SiC}+$ Egg Shell (SE) & 2250 & $3^{0}$ \\
4 & $\mathrm{Al}_{2} \mathrm{O}_{3}+$ Egg Shell (AE) & 920 & $2^{0}$ \\
5 & $\mathrm{Al}_{2} \mathrm{O}_{3}+$ Egg Shell (AE) & 1550 & $3^{0}$ \\
6 & $\mathrm{Al}_{2} \mathrm{O}_{3}+$ Egg Shell (AE) & 2250 & $1^{0}$ \\
7 & $\mathrm{Ti}+$ Egg Shell (TE) & 920 & $3^{0}$ \\
8 & $\mathrm{Ti}+$ Egg Shell (TE) & 1550 & $1^{0}$ \\
9 & $\mathrm{Ti}+$ Egg Shell (TE) & 2250 & $2^{0}$ \\
\hline
\end{tabular}

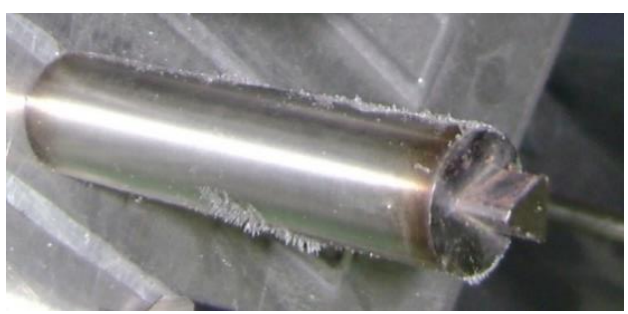

Figure 4. FSP tool

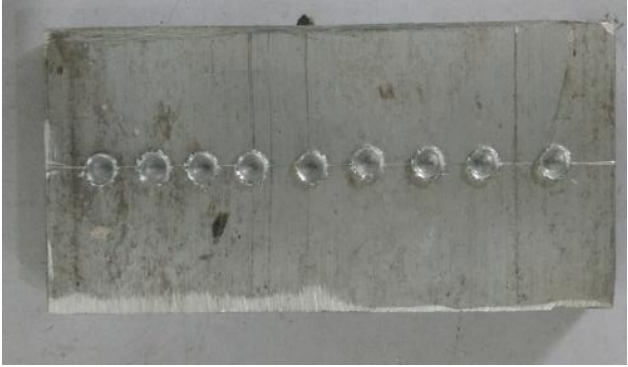

Figure 5. FSP workpiece preparation

\section{RESULT AND DISCUSSION}

After fabrication hardness was observed with the help of hardness tester and results are tabulated in Table 3. The base metal hardness was tested as 92 HRB (Hardness, Rockwell B) and fabricated composites were showing good improvement after reinforcement and FSP. The mean responses of fabricated raw data and Signal to Noise $(\mathrm{S} / \mathrm{N})$ ratios of hardness for each process parameter at all levels were calculated by Minitab 19 software and are presented in Table 4, 5, 6, 7 and 8 .

The average Signal-to-Noise ratios and average values of Mean for at all levels are tabulated in Table 8.

Analysis of variance result for Signal-to-Noise ratios and means of hardness were observed that the third process parameter (i.e. tool angle) is insignificant. To identify the significant process parameters in hardness testing the pooled version of ANOVA is calculated through software. The pooled analysis of variance for hardness is given in Table 8 . This gives a strong indication that reinforcement (RF) and tool speed (TS) significantly affect the $\mathrm{S} / \mathrm{N}$ ratio and mean.

It is evident from Figure 7 and Figure 8 that the hardness is highest at the third level of reinforcement i.e. Ti + Egg Shell (TE), third level of tool revolving speed (TS, i.e. $2250 \mathrm{rpm}$ ) and second level of tilt angle (TA, i.e. $2^{0}$ ). The $\mathrm{S} / \mathrm{N}$ ratio plot also proposes the same levels as the best level for the maximum hardness of FSP composite. Three confirmation experiments were conducted at the optimal level of process parameters. The average mean value of the tensile strength and hardness of FSP is found within the confidence interval as reported in Table 9.

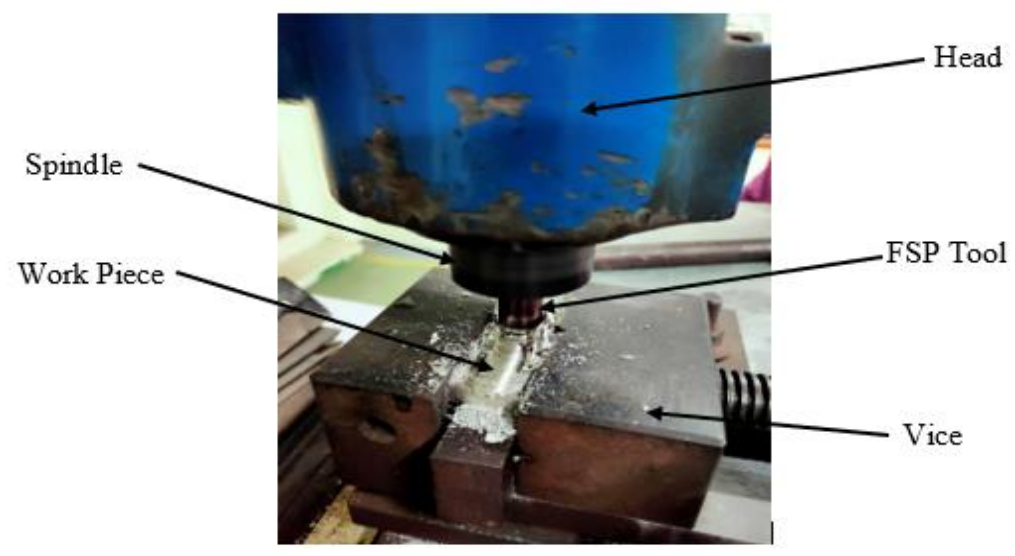

Figure 6. FSP Setup 
Table 3. Experimental hardness

\begin{tabular}{ccccc}
\hline S. No. & Reinforcement (RF) & Tool Speed in rpm (TS) & Tilt Angle in degree (TA) & Hardness (HRB) \\
\hline 1 & SiC+ Egg Shell (SE) & 920 & $1^{0}$ & 97 \\
2 & $\mathrm{SiC}+$ Egg Shell (SE) & 1550 & $2^{0}$ & 108 \\
3 & $\mathrm{SiC}+$ Egg Shell (SE) & 2250 & $3^{0}$ & 114 \\
4 & $\mathrm{Al}_{2} \mathrm{O}_{3}+$ Egg Shell (AE) & 920 & $2^{0}$ & 103 \\
5 & $\mathrm{Al}_{2} \mathrm{O}_{3}+$ Egg Shell (AE) & 1550 & $3^{0}$ & 112 \\
6 & $\mathrm{Al}_{2} \mathrm{O}_{3}+$ Egg Shell (AE) & 2250 & $1^{0}$ & 119 \\
7 & $\mathrm{Ti}+$ Egg Shell (TE) & 920 & $3^{0}$ & 115 \\
8 & Ti+ Egg Shell (TE) & 1550 & $1^{0}$ & 124 \\
9 & Ti+ Egg Shell (TE) & 2250 & $2^{0}$ & 132 \\
\hline
\end{tabular}

Table 4. Estimated Model Coefficients for SN ratios

\begin{tabular}{ccccc}
\hline Term & Coef & SE Coef & T & P \\
\hline Constant & 41.0875 & 0.02522 & 1629.129 & 0.000 \\
RF SE & -0.5735 & 0.03567 & -16.080 & 0.004 \\
RF AE & -0.1702 & 0.03567 & -4.772 & 0.041 \\
TS 920 & -0.6855 & 0.03567 & -19.219 & 0.003 \\
TS 1550 & 0.0862 & 0.03567 & 2.417 & 0.137 \\
TA 1 & -0.0493 & 0.03567 & -1.382 & 0.301 \\
TA 2 & 0.0247 & 0.03567 & 0.692 & 0.560 \\
\hline
\end{tabular}

Table 5. Analysis of variance for SN ratios

\begin{tabular}{ccccccc}
\hline Source & DF & Seq SS & Adj SS & Adj MS & F & P \\
\hline RF & 2 & 2.73322 & 2.73322 & 1.36661 & 238.72 & $0.004^{*}$ \\
TS & 2 & 2.50948 & 2.50948 & 1.25474 & 219.18 & $0.005^{*}$ \\
TA & 2 & 0.01093 & 0.01093 & 0.00546 & 0.95 & 0.512 \\
Residual Error & 2 & 0.01145 & 0.01145 & 0.00572 & & \\
Total & 8 & 5.26508 & & & & \\
\hline
\end{tabular}

$\mathrm{S}=0.0757 ; \mathrm{R}-\mathrm{Sq}=99.78 \% ; \mathrm{R}-\mathrm{Sq}(\mathrm{adj})=99.13 \% ;$ Order of Significance: $1 . \mathrm{RF}, 2 . \mathrm{TS} ; *$ Significance at $95 \%$ level.

Table 6. Estimated model coefficients for means

\begin{tabular}{ccccc}
\hline Term & Coef & SE Coef & T & P \\
\hline Constant & 113.778 & 0.1111 & 1024.000 & 0.000 \\
RF SE & -7.444 & 0.1571 & -47.376 & 0.000 \\
RF AE & -2.444 & 0.1571 & -15.556 & 0.004 \\
TS 920 & -8.778 & 0.1571 & -55.861 & 0.000 \\
TS 1550 & 0.889 & 0.1571 & 5.657 & 0.030 \\
TA 1 & -0.444 & 0.1571 & -2.828 & 0.106 \\
TA 2 & 0.556 & 0.1571 & 3.536 & 0.072 \\
\hline
\end{tabular}

Table 7. Analysis of variance for means

\begin{tabular}{ccccccc}
\hline Source & DF & Seq SS & Adj SS & Adj MS & F & P \\
\hline RF & 2 & 477.556 & 477.556 & 238.778 & 2149.00 & $0.000^{*}$ \\
TS & 2 & 420.222 & 420.222 & 210.111 & 1891.00 & $0.001^{*}$ \\
TA & 2 & 1.556 & 1.556 & 0.778 & 7.00 & 0.125 \\
Residual Error & 2 & 0.222 & 0.222 & 0.111 & & \\
Total & 8 & 899.556 & & & &
\end{tabular}

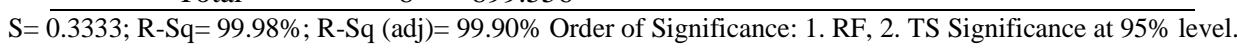

Table 8. Response table for signal to noise ratios and mean larger is better

\begin{tabular}{cccccccc}
\hline & \multicolumn{3}{c}{ For SN } & & \multicolumn{3}{c}{ For Mean } \\
\cline { 1 - 3 } \cline { 6 - 8 } Level & RF & TS & TA & & RF & TS & TA \\
\hline 1 & 40.51 & 40.40 & 41.04 & & 106.3 & 105.0 & 113.3 \\
2 & 40.92 & 41.17 & 41.11 & & 111.3 & 114.7 & 114.3 \\
3 & 41.83 & 41.69 & 41.11 & & 123.7 & 121.7 & 113.7 \\
Delta & 1.32 & 1.28 & 0.07 & & 17.3 & 16.7 & 1.0 \\
Rank & 1 & 2 & 3 & & 1 & 2 & 3 \\
\hline
\end{tabular}




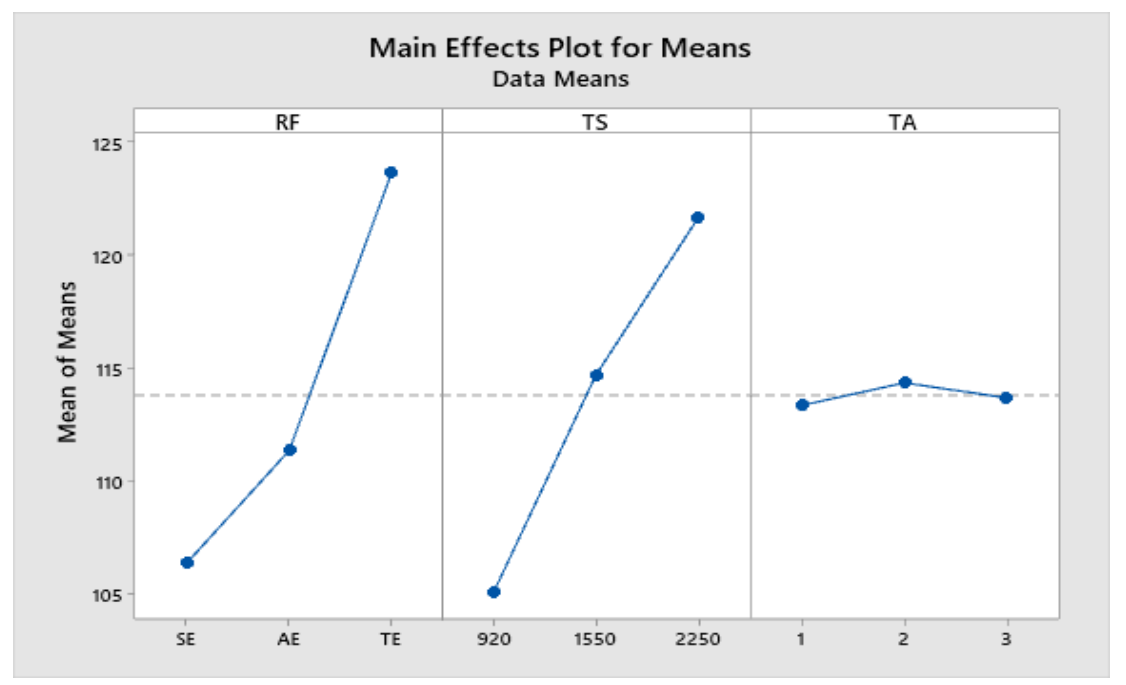

Figure 7. Effects of process parameters on hardness (S/N effects)

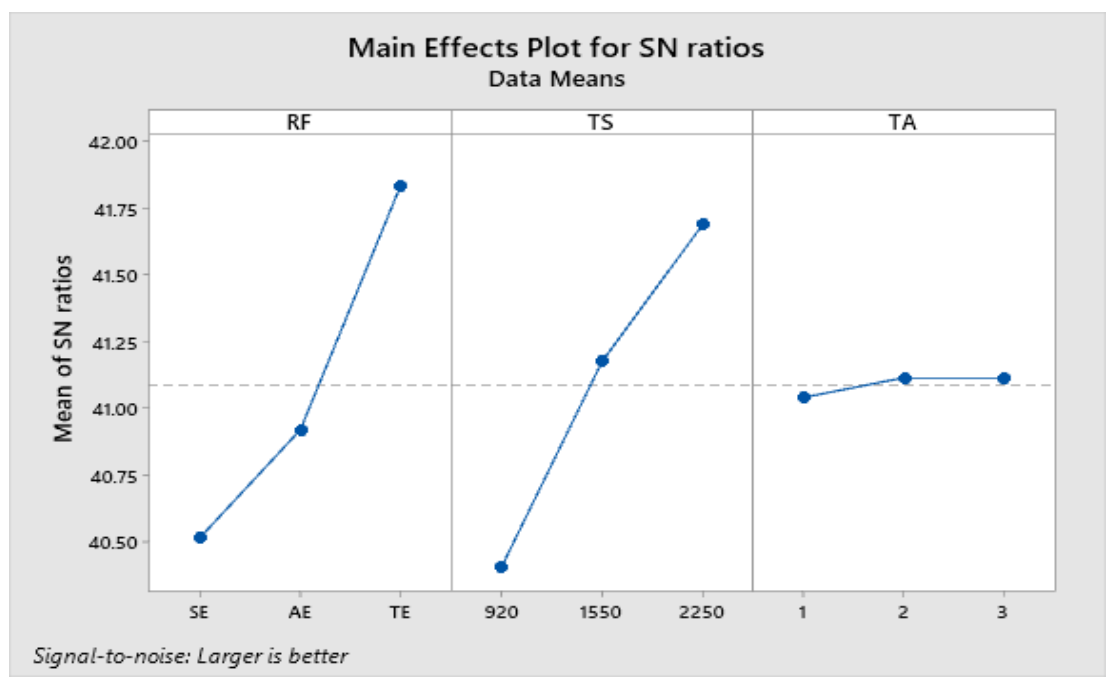

Figure 8. Effects of process parameters on hardness (main effects)

Table 9. Responses at optimum levels of process parameters

\begin{tabular}{ccc}
\hline Responses & $\begin{array}{c}\text { Predicted mean } \\
\text { values }\end{array}$ & $\begin{array}{c}\text { Experimental } \\
\text { values (average) }\end{array}$ \\
\hline Hardness (HRB) & 132 & 130 \\
\hline
\end{tabular}

\section{CONCLUSION}

In the present study, the hybrid green metal matrix of $\mathrm{SiC} / \mathrm{Al}_{2} \mathrm{O}_{3} / \mathrm{Ti}$ with eggshell was produced and mechanical properties (hardness) of composites were investigated. Based on the experimental results, the following conclusions were drawn for the proposed set of process parameters:

(1) It is found that parent metal A7075 alloy with reinforcement of $\mathrm{SiC} / \mathrm{Al}_{2} \mathrm{O}_{3} / \mathrm{Ti}$ along with waste material (i.e. eggshell) possess good characteristics for FSP.

(2) It observed that the Reinforcement (RF) and Tool Speed (TS) are significant parameters for hardness and tilt angle is an insignificant parameter for hardness.

(3) The optimum set of process parameters for FSP of A7075 alloy with reinforcement of $\mathrm{SiC} / \mathrm{Al}_{2} \mathrm{O}_{3} / \mathrm{Ti}$ along with waste material (i.e. eggshell) has been produced good characteristics surface composite are $\mathrm{RF}=\mathrm{Ti}+\mathrm{Egg}$ Shell, $\mathrm{TS}=2250 \mathrm{rpm}$ and $\mathrm{TA}=2^{0}$.
(4) Hardness increases with increase the tool speed up to some extent and reinforcement with Ti gives maximum values with waste material (eggshell).

(5) The range of optimum values of hardness is found between 130 to 132 for the selected optimum process parameters.

\section{ACKNOWLEDGMENTS}

The authors are grateful to Dr. A.P.J. Abdul Kalam Technical University, Lucknow, Uttar Pradesh, India for supporting the project under Collaborative Research and Innovation Program (CRIP) funded by TEQIP-III AKTU (CRIP's letter No: AKTU/Dean-PGSR/2019/CRIP/ 29). The authors acknowledge the use of the Facilities available at Noida Institute of Engineering \& Technology, Greater Noida, GB Nagar, U.P. India for their support in carrying out the experimental and characterization works.

\section{REFERENCES}

[1] Srivastava, A.K., Dixit, A.R., Tiwari, S. (2016). A review on the intensification of metal matrix composites and its nonconventional machining. Science and 
Engineering of Composite Materials, 25(2): 213-228. https://doi.org/10.1515/secm-2015-0287

[2] Srivastava, A.K., Dixit, A.R., Tiwari, S. (2016). Investigation of microstructural and mechanical properties of metal matrix composite A359/B ${ }_{4} \mathrm{C}$ through electromagnetic stir casting. Indian Journal of Engineering \& Materials Sciences, 23: 171-180.

[3] Kumar, S., Srivastava, A.K., Singh, R.K., Dwivedi, S.P. (2019). Experimental study on hardness and fatigue behavior in joining of AA5083 and AA6063 by friction stir welding. Materials Today: Proceedings. https://doi.org/10.1016/j.matpr.2019.07.535

[4] Sarmadi, H., Kokabi, A.H., Reihani, S.S.M. (2013). Friction and wear performance of copper-graphite surface composites fabricated by friction stir processing (FSP). Wear, 304(1-2): 1-12. https://doi.org/10.1016/j.wear.2013.04.023

[5] Singh, S., Pal, K. (2017). Effect of texture evolution on mechanical and damping properties of $\mathrm{SiC} / \mathrm{ZnAl}_{2} \mathrm{O}_{4} / \mathrm{Al}$ composite through friction stir Processing. International Journal of Materials Research and Technology, 8(1): 22232. https://doi.org/10.1016/j.jmrt.2017.07.006

[6] Zhao, Y.T., Kai, X.Z., Chen,G., Lin, W.L., Wang, C.M. (2016). Effects of friction stir processing on the microstructure and superplasticity of in situ nano$\mathrm{ZrB} 2 / 2024 \mathrm{Al}$ composite. International Materials Progress in Natural Science, 26(1): 69-77. https://doi.org/10.1016/j.pnsc.2016.01.009

[7] Thangarasua, A., Muruganb, N., Dinaharan, I. (2014). Production and wear characterization of AA6082 -TiC surface composites by friction stir processing. Procedia Engineering, 97: 590-597. https://doi.org/10.1016/j.proeng.2014.12.287

[8] Chainarong, S., Muangjunburee, P., Suthummanon, S. (2014). Friction stir processing of SSM356 aluminum alloy. Procedia Engineering, 97: 732-740. https://doi.org/10.1016/j.proeng.2014.12.303

[9] Dinaharan, I. (2016). Influence of ceramic particulate type on microstructure and tensile strength of aluminum matrix composites produced using friction stir processing.
Journal of Asian Ceramic Societies, 4(2): 209-218. https://doi.org/10.1016/j.jascer.2016.04.002

[10] Abraham, S.J., Madane, S.C.R., Dinaharan, I., Baruch, L.J. (2016). Development of quartz particulate reinforced AA6063 aluminum matrix composites via friction stir processing. Journal of Asian Ceramic Societies, 4(4): 381-389. https://doi.org/10.1016/j.jascer.2016.08.001

[11] Dinaharan, I., Saravanakumar, S., Kalaiselvan, K., Gopalakrishnan, S. (2017). Microstructure and sliding wear characterization of $\mathrm{Cu} / \mathrm{TiB}_{2}$ copper matrix composites fabricated via friction stir processing. Journal of Asian Ceramic Societies, 5(3): 295-303. https://doi.org/10.1016/j.jascer.2017.06.002

[12] Rana, H.G., Badheka, V.J., Kumar, A. (2016). Fabrication of A17075 / B 4 C surface composite by novel Friction Stir Processing (FSP) and investigation on wear properties. Procedia Technology, 23: 519-528. https://doi.org/10.1016/j.protcy.2016.03.058

[13] Sunil, R.B., Reddy, G.P.K., Patle, H., Dumpala, R. (2016). Magnesium based surface metal matrix composites by friction stir processing. International Journal of Magnesium and Alloys, 4(1): 52-61. https://doi.org/10.1016/j.jma.2016.02.001

[14] Ahmadkhaniha, D., Sohi, H.M., Salehi, A., Tahavvori, R. (2016). Formations of $\mathrm{AZ} 91 / \mathrm{Al}_{2} \mathrm{O}_{3}$ nano-composite layer by friction stir processing. International Journal of Magnesium and Alloys, 4(4): 314-318. https://doi.org/10.1016/j.jma.2016.11.002

[15] Raju, S.L., Kumar, A. (2014). Influence of $\mathrm{Al}_{2} \mathrm{O}_{3}$ particles on the microstructure and mechanical properties of copper surface composites fabricated by friction stir processing. International Journal of Defence Technology, 10(4): 375-383. https://doi.org/10.1016/j.dt.2014.09.001

[16] Rathee, S., Maheshwari, S., Siddiquee, A.N., Srivastava, M. (2016). Effect of tool plunge depth on reinforcement particle distribution in surface composite fabrication via friction stir processing. International Journal of Defence Technology, 13(2): 86-91. https://doi.org/10.1016/j.dt.2016.11.003 